\title{
nature
}

20 March 1997 Volume 386 Issue no 6622

\section{A belated agreement that requires faster progress}

The treatment of contract and postdoctoral researchers by employers is notoriously casual. A year-old initiative to improve matters in Britain may provide an example to others, but has a long way to go.

S ome professors have not even heard of it. Some are implementing it conscientiously. Those in universities who are supposed to benefit are beginning to - but by no means enough of them, and to too little an extent. Those employed by the government are seeing little progress.

"It" is a concordat, announced almost exactly a year ago today, between British university vice-chancellors and research funding councils. It is intended to underpin the provision of employment rights and support for "them" - the great underclass of research in Britain: postdoctoral and other contract researchers. Recent articles and correspondence in Nature suggest that Britain is far from being the only country in which these researchers are relied upon while simultaneously undervalued. Yet still young scientists apply in droves for postdoctoral research posts.

The concordat does not address pay scales, in respect of which conditions of postdoctoral employment have recently improved in UK universities. Rather, it is intended to ensure that contract researchers obtain just treatment in maternity leave, salaries that reflect experience and seniority, adequate training and conscientious monitoring of progress and career advice.

Soundings within the UK university community suggest that progress with the concordat is patchy. The scheme began to be implemented only six months ago. All publicly funded universities and research councils must implement it and at senior levels are indeed doing so. But what goes on at the top of an institution does not always readily translate into action three or four levels down. Issues are already emerging about which more action is necessary.

One concerns a tendency for academics, seeking to employ

\section{Discovery delocalized}

\section{The timing of celebrations of J. J. Thomson's discovery of the electron is necessarily arbitrary.}

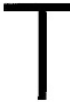

he two-slit experiment shows how the same electron pops up, disconcertingly, in at least two places at once. Such positional uncertainty applies to the discovery of the electron itself. On 21 and 22 March, the University of Cambridge celebrates the centenary of that achievement by its very own J. J. Thomson. Thomson announced the finding at the Royal Institution on 30 April 1897, but Cambridge's error in celebrating a centenary after only 99.98 years is as a proportion less than those of Thomson's original estimates of the mass and charge of his 'corpuscle'. It is in fact doubly pardonable, as the centenary adds a historical resonance to this, Britain's National Science, Engineering and Technology week.

Although posterity has awarded the crown for the discovery to Thomson, Emil Wiechert gave the first account of a negatively charged atomic constituent to the Königsberg Physikalisch-ökonomische Gesellschaft on 7 January 1897 - Thomson did not publish his findings until October. Either of those dates could serve as the centenary. Being the reputable journal that we are, we could suggest that celebra- researchers on a contract, to apply for grants and bid low down the pay scale, even if the researcher merits more. There are signs that this is happening despite an explicit allowance within the concordat for research councils to provide enhanced pay where appropriate. Unless grant applicants are given stronger encouragement in this regard, experienced senior contract staff will continue often to be underpaid.

The provisions for supporting maternity leave appear to be working. But a researcher who moves from one contract to another, even if funded by the same research council but at a different university, comes under a new employer. He or she loses employment rights that would have been accrued had he or she stayed still.

All that being said, postdoctoral researchers in universities are experiencing significantly more progress than those employed directly by the very body that backed the concordat in the first place - the British government. Research councils merit scrutiny here. The Medical Research Council, with an increasing proportion of contract researchers on its books as older permanent researchers retire, announced last October its intention to pursue concordat-like measures for its staff. It admits that it still has some way to go. The Natural Environment Research Council's enlightened policy is that any employee of more than five years' standing should be permanent. Unfortunately, many such employees are still impermanent.

The concordat is a step towards righting a scandalous state of affairs that persisted for far too long. Its example should stimulate researchers in some other countries to demand similar measures. Every means should be found to keep up the pressure on all employers who keep contract researchers, doing work of central importance, in a state of unjust personal disadvantage.

tions be postponed until the publication date of October, rather than being pinned to a Victorian equivalent of a press conference in April.

In truth, the timing does not matter. No discovery is made in isolation, and indeed the finding of the electron was a less singular event than many other discoveries of fundamental entities. Arguably, it began with the first quasi-description of the thermionic effect, by du Fay in 1733, and included Millikan's work on the charge on the electron in the 1930s. Furthermore, as Steven Weinberg describes on pages 213-215, the discovery of the electron is still unfolding: although its mass and charge are well established, nobody yet knows why these properties have the values they do - although string theorists are working on it. In short, from a truly Olympian viewpoint, the uncovering of the electron might be seen as akin to the classic quantum description of a single free elementary particle - an unbounded field of endeavour, for which one date of commemoration is as good as any other. But, some time in 1897 , we became confident that, whatever it truly is, it is there. 